\title{
Post-Development Possibilities: A conversation
}

\author{
Arturo Escobar and Wendy Harcourt
}

Email: harcourt@iss.nl

\section{Arturo Escobar}

Affiliation: Department of Anthropology University of North Carolina at Chapel Hill City and country: Chapel Hill, USA

\section{Wendy Harcourt \\ Affiliation: International Institute of Social Studies of Erasmus University Rotterdam City and country: The Hague, The Netherlands}

\section{Running Header: Duo-Dialogue on Post-Development Possibilities}

Wendy Harcourt was Editor of Development from 1988 - 2012 and Arturo Escobar a member of the Editorial board from 1993 - 2012. Together they co-edited several issues of Development and contributed individually and jointly editorials and papers particularly in the early 2000s when they co-lead a project on Women and the Politics of Place. Both are currently university professors teaching post-development: Arturo at the University of North Carolina at Chapel Hill, USA and Wendy at the International Institute of Social Studies of Erasmus University Rotterdam in The Hague, The Netherlands. In the following conversation they explore their continued interests in post-development, ecology and gender as part of the critical debates around development practice and theory today.

WH: I see post-development as an important approach to development, that indeed has informed many of the articles in the Development journal in the 1990s and 2000s. Your work has led the debate, and we have both written, among other things, on post-development in different publications. In summary, I would say post development helps us to recognize different realities, biases and opinions informing development - from the highly technical experience of governments; to the aspirations of social movements for human rights in large cities; to projects which aim to provide food security, clean water and better education in rural villages. It also allows us to understand development as complex economic, social and political processes at individual, local, state regional and global level and to look at the how actors operate in development on different scales. It draws attention both to the particularity of professional expert knowledge and to the knowledge of people living the changes brought about by development in different locations and institutions. It also underlines how development happens differently according to which environment, which culture(s) what race or gender regime dominates. Most importantly it underscores how development is shaped by racialized and gender histories dominated by European/US/ OECD countries stretching back to the colonial period, even if development as a term came into being after the second world war with President Truman's famous speech.

Wolfgang Sachs, our good friend and also former editor of Development, has argued that western technocratic processes of development have silenced other cultures and peoples' ways of living. He brought attention to development as part of the problem of injustice and inequalities for economically marginalized people. I think we would both agree with him that post-development processes need to be rooted in the agency of local communities who identify their own problems 
and to move away from development as a western dominated ideology and a form of cultural imperialism.

A question I know you are often asked is whether this emphasis of going 'beyond' development means romanticizing non-modernity and denying the desires of economically marginalized to be part of the modern consumer age. How do you respond to such questions about post development as romantic or unrealistic?

AE: Given the social and ecological devastation brought about by modern development practices and giving the huge increases in inequality and climate crisis, I would argue it is 'romantic' to think that more of the same approach of current development practices are going to lead to any real improvement. At the same time, as another friend, Boaventura de Sousa Santos suggests, we are now facing modern problems for which there are no longer modern solutions. For me growing consumerism and individualism is a damaging nightmare. I prefer to learn from the life giving projects which have emerged for example, in Chiapas, Oaxaca and the Norte del Cauca in Colombia's southwest. The debates on buen vivir of the last decade indicate how indigenous and popular communities are creating their own forms of modernity. These diverse worlds move in several directions working with and outside the 'modern world' and its practices and technologies.

In a conversation recently with Gustavo Esteva (Esteva and Escobar. 2017) I spoke about three levels of cooperation which I moves us beyond this idea of looking at grassroots as romantic and 'unrealistic'. what I said in the following:

(1) Cooperation as development aid: this is the standard form of cooperation, practiced by institution such as US AID, the World Bank and mainstream NGOs. It takes for granted the dominant world (in terms of markets, individual actions, productivity, etc.).

(2) Cooperation as, or for, social justice: this is the kind of cooperation practiced with the intention of fostering greater social justice and environmental sustainability; it embraces human rights (including gender and ethnic diversity), environ- mental justice, the reduction of inequality, direct support for grassroots groups, and so forth.

(3) Cooperation for civilizational transitions or cooperation for autonomy. What is interesting is that this form would go beyond the binary of 'us' (who have) and 'them' (who need), and embrace all sides in the same, though diverse, movement for civilizational transitions and inter-autonomy, that is, coalitions and meshworks of autonomous collectives and communities from both the Global North and the Global South.

WH: These are useful definitions for how to 'do' post-development, including how to teach postdevelopment. Like you, I am interested in how to use post-development to produce more progressive theory and practice by fundamentally questioning 'development'. I see postdevelopment criticism of economic and ecological models as extremely important in finding people and place based 'alternatives to development'? When I teach post-development I have been directly inspired by your work and ask my students who are post graduates $95 \%$ from the countries in the Global South, to reflect critically on their experiences of living and doing development - asking them to describe and analyze where and how have they encountered the making of development. I see this exercise and the whole MA course responding to the postdevelopment call for the unmaking of development through the intervention of new narratives, new ways of thinking and doing, to which I have added the remaking of development. 
I wanted to ask you about another interesting intellectual project which I see as contributing to the remaking of the development lexicon - the Post-Development Dictionary, which you co-edited along with Ashish Kothari, Ariel Salleh, Federico Demaria and Alberto Acosta with over 100 entries. I wanted to ask about the framing of the book as I hope it will be a defining text for postdevelopment - particularly for teaching. How is it tackling the idea of 'universality' - in modernity the idea that we all live in a single, globalized, world, and the idea of development based on science as the only reliable truth and 'harbinger of progress'? I find being critical of universality and appealing to pluriversality can be difficult as students are taught to look for universal solutions, rationality and modernity as the only way to progress.

AE: Some see the condemnation of modernity as not fair because the West itself is plural, inhabited by dissenting voices and plural modernities. I think it is important to acknowledge there are many forms of modernity and that there are non-dominant Wests in West. At the same time we have to understand modernity, and its message of universality using a post-development lens, in other words, by acknowledging the privileges accorded to all things European (especially white male, able bodied European bodies). We need to question dominant western views of modernity as de facto the only site of reason, progress, civility and so forth that is based on the non-viability of other worlds.

My response is to look at the pluriverse 'a world where many worlds can be embraced', according to Zapatistas. My critique is in not really 'anti-European' or 'anti-West', or 'anti-modern'. Instead I aim to defend non-dominant worlds that, while engaged with modernity and event deeply shaped by it, nevertheless exceed it, that is, cannot be reduced to it; indigenous worlds, for instance, can be both modern and radically different as well. This is clear in peoples' struggles to construct territories for re-existence in ways that, for instance, do not abide by the modern dictate of separating humans and nonhumans (when arguing, for instance, that mountains, or rivers, are sacred beings). I think we are in a civilizational crossroads and we need to live in multiple worlds and to look at constructing other forms of re-existence. I would include here how to cultivate lives that are autonomous, convivial and communal. This means, very practically the re-localization of food, energy, transportation, health, etc. and the re-communalization of social life reconnecting with other humans and non-humans, including the spiritual world. These are important principles for all of us, indeed, in contrast to the usual development subjects, perhaps it is most important question for those living in the densest and most consumption-oriented worlds, namely, the middle classes worldwide.

WH: I agree that we need to be now thinking of post-development in very concrete ways. For me the debates on alternatives also in Europe - such as transition towns, degrowth movement and slow food have a lot to contribute to seeing how to make it tangible and realizable. As you know $I$ am now beginning a project on well-being, ecology, gender and community (WEGO) ${ }^{1}$ that will conduct evidence-based research that looks at gendered ecological practices in place and among communities, exploring what is happening in specific places which are negotiating life and livelihoods in human damaged environments. In this exploration of sustainability among communities, WEGO also calls attention to emotions, feelings, the spiritual, non-scientific knowledges and interactions with non-humans, with technologies, life and death. It is very much a post-development project as WEGO will build from local engagement and knowledge of peoples' practices and visions of how to live on this planet under climatic conditions never before

${ }^{1}$ For more on WEGO please see: https://wegoitn.com/ 
experienced. the 18 research institutes and $15 \mathrm{PhD}$ students will co-produce knowledge on how hybrid and emergent ecologies are creating new forms of livelihoods and care activities, in response to growing lack of resilience of the economy and ecosystem. WEGO will aim to combine a gendered knowledge of every day experiences of environmental practices with a politically aware approach to social and environmental dynamics in three themes: Climate Change, Economic Development and Extractivism; Commoning, Community Economies and the Politics of Care; and Nature/Culture/ Embodiment and Technologies.

AE: I like the sound of WEGO, it resonates well with the critical frame of the Post -Development Dictionary - it is not surprising that we asked you to contribute an entry on body politics! As we write in our introduction to the Dictionary, we look at radical and systemic alternatives ranging from long-standing indigenous worldviews, older philosophies and religious traditions to recent social movements. Some entries look at what has gone wrong, while others examine what a better life would look like. Our aim is to open up a space of alternatives. For instance, buen vivir, 'a culture of life' with various names throughout South America; ubuntu, emphasizing the southern African value of human mutuality; swaraj from India, centred on self-reliance and self-governance. We consider that there are thousands of such models around the world, and together, these perspectives compose a pluriverse.

We hope that the Post-Development Dictionary will deepen and widen an agenda for research, dialogue and action, for scholars, policymakers and activists. We are interested in reflective elements of major religions including Islam, Christianity, Hinduism, Buddhism, and Judaism as well as the political visions of eco-socialism and deep ecology which co-exist with contemporary concepts such as degrowth and ecofeminism. By offering a variety of worldviews and practices we hope it will help us further in the search for an ecologically wise and socially just world. We see these transformative alternatives as different from mainstream or reformist solutions in a number of ways. They go to the roots of a problem and they question the core features of development discourse such as economic growth, the rhetoric of progress, instrumental rationality, markets, universality, anthropocentrism, racism and sexism. They aim to encompass radically different ethics grounded in a relational logic; a world where everything is connected to everything else.

\section{Reference}

Esteva, Gustavo and Arturo Escobar. 2017. Post-Development @ 25: on 'being stuck' and moving forward, sideways, backward and otherwise, Third World Quarterly, 38:12, 2559-2572, DOI: 10.1080/01436597.2017.1334545 